\title{
Effect of Insulation Properties on the Field Grading of Solid Dielectric DC Cable
}

Boggs, S.; Damon, Dwight Hill; Hjerrild, Jesper; Holbøll, Joachim; Henriksen, Mogens

Published in:

IEEE Power Engineering Review

Link to article, DOI:

10.1109/MPER.2001.4311538

Publication date:

2001

Document Version

Publisher's PDF, also known as Version of record

Link back to DTU Orbit

Citation (APA):

Boggs, S., Damon, D. H., Hjerrild, J., Holbøll, J., \& Henriksen, M. (2001). Effect of Insulation Properties on the Field Grading of Solid Dielectric DC Cable. IEEE Power Engineering Review, 21(8), 56.

https://doi.org/10.1109/MPER.2001.4311538

\section{General rights}

Copyright and moral rights for the publications made accessible in the public portal are retained by the authors and/or other copyright owners and it is a condition of accessing publications that users recognise and abide by the legal requirements associated with these rights.

- Users may download and print one copy of any publication from the public portal for the purpose of private study or research.

- You may not further distribute the material or use it for any profit-making activity or commercial gain

- You may freely distribute the URL identifying the publication in the public portal 
Abstract: Conventional loading of induction motors is an extremely difficult and expensive process for large machines. In those cases, full load losses and temperature rise can be estimated by means of equivalent loading methods, which provide an accurate alternative, without the need of a mechanical load applied to the shaft. This paper describes three such methods, all using a commercial PWM inverter. The methods examined are described in detail and the results of tests performed on a $10 \mathrm{hp}$ induction motor are presented. A calorimetric measurement facility was used in order to ensure consistency of result comparison between the different methods, as well as high accuracy for total loss measurement. The measured values of losses and temperature rise, although marginally larger, are in good agreement with those obtained through conventional loading.

Keywords: Heat run test, temperature measurement, machine testing, losses in electrical machines, equivalent loading, calorimetric measurement.

Preprint Order Number: PE-076EC (05-2001)

Discussion Deadline: October 2001

\section{Energy Development and Power Generation}

\section{Normalized Power Curves as a Tool for Identification of Optimum Wind Turbine Generator Parameters}

Rau, V.G.; Jangamshetti, S.H.

Author Affiliation: Indian Institute of Technology

Abstract: This paper presents a novel method of matching wind turbine generators to a site using normalized power and capacity factor curves. The site matching is based on identifying optimum turbine speed parameters from the turbine performance index curve, which is obtained from the normalized curves, so as to yield higher energy production at a higher capacity factor. The wind speeds are parameterized using a cubic mean cuberoot and statistically modeled using the Weibull probability density function. An expression for a normalized power and capacity factor, expressed entirely in normalized rated speed, is derived. The wind turbine performance index, a new ranking parameter, is defined to optimally match turbines to a potential wind site. The plots of normalized power, capacity factor, and turbine performance index versus normalized rated wind speed are drawn for a known value of the Weibull shape parameter of a site. Usefulness of these normalized curves for identifying optimum wind turbine generator parameters for a site is presented by means of two illustrative case studies. The generalized curves, if used at the planning and development stages of wind power stations, will serve as a useful tool to make a judicious choice of a wind turbine generator that yields higher energy at a higher capacity factor.

Keywords: Capacity factors, normalized power curves, normalized rated wind speed, turbine performance index, Weibull probability density function, wind turbine generator.

Preprint Order Number: PE-023EC (05-2001)

Discussion Deadline: October 2001

\section{Insulated Conductors}

\section{Computation of Thermal-Chemical Phenomena} Related to High-Temperature HPFF Cable Operation

Kuang, J.; Boggs, S.

Author Affiliation: University of Toronto, Toronto, Canada; University of Connecticut, Storrs, CT

Abstract: We report transient nonlinear finite element computations of the coupled electric and thermal fields undertaken to explain defected-induced thermal runaway of an HPFF cable under highly accelerated test conditions. These computations include the effects of temperature- and moisture-dependent $\tan (\delta)$, temperature-dependent evolution of moisture, temperature-dependent evolution of $\mathrm{CO}$, and temperature-dependent saturation concentration of $\mathrm{CO}$. Computations were also undertaken for a range of boundary conditions. Comparison between the computed results and measured data suggest the appropriate boundary conditions for such computations. We conclude that thermal runaway probably occurred locally, so that axial heat flow down the conductor results in substantially constant conductor temperature during thermal runaway.

Preprint Order Number: Pe-367PRD (05-2001)

Discussion Deadline: October 2001

\section{Effect of Insulation Properties on the Field Grading of Solid Dielectric DC Cable}

Boggs, S.; Damon, D.; Hjerrild, J.; Holboll, J.; Henriksen, M.

Author Affiliation: University of Connecticut, Storrs, CT; Technical University of Denmark, Denmark

Abstract: The development of solid dielectric dc transmission class cable is a priority throughout much of the world, to avoid risks associated with placing hydrocarbon fluids in underwater environments. The conductivity of polymeric solid dielectrics tends to be a strong function of temperature and electric field, however. Based on measured material properties, we demonstrate the effect of such dependencies on the field grading of dc cable for the range of measured material properties and provide an analytical approximation for computing the field of resistively graded dielectrics, including the effect of temperature and field-dependent conductivity.

Preprint Order Number: PE-752PRD (05-2001)

Discussion Deadline: October 2001

\section{Power System Analysis, Computing, and Economics}

Bibliography on the Application

of Probability Methods in Power System Reliability Evaluation 1996-1999

Billinton R.; Fotuhi-Firuzabad, M.; Bertling, L.

Author Affiliation: University of Saskatchewan, Canada; Kungl Tekniska Hogskolan

Abstract: This paper presents a bibliography of papers on the subject of power system reliability evaluation. Papers in such areas as probabilistic load flow, probabilistic production costing, probabilistic transient stability evaluation, etc. have not been included except where they specifically address power system reliability evaluation.

The bibliography includes material made available since the publication of six previous papers, "Bibliography on the Application of Probability Methods in Power System Reliability Evaluation," IEEE Transactions on Power Apparatus and Systems PAS-91, 1972, pp. 649-660; Pas-97, 1978, pp. 2235-2242; PAS-103, 1984, pp. 275-282; IEEE Transactions on Power Systems, vol. 3, Nov. 1988, pp. 1555-1564; vol. 9, Feb. 1994, pp. 41-49; and vol. 14, Feb. 1999, pp. 51-57.

Preprint Order Number: PE-541 PRS (05-2001)

Discussion Deadline: October 2001

\section{Fuzzy Second Correction on the Complementary Condition for Optimal Power Flows}

Wu, Y-C.

Author Affiliation: National Lien-Ho Institute of Technology

Abstract: In this paper, an efficient fuzzy second correction scheme (FSCS) to improve the complementarity condition in a predictor-corrector interior point algorithm (PCIPA) for optimal power flows (OPF) is proposed. At every iteration, the proposed FSCS estimates, 